\title{
Was soll das?
}

\section{Editorial}

_ Unfassbar! Das war meine erste Reaktion, als ich von den Erfahrungen der Praxisinhaber mit den Krankenkassen hörte ( $\odot$ im Leserforum und im Artikel ab Seite 8). Zeit ist Geld - diese Binsenweisheit aus der Wirtschaft nehmen sich Ergotherapeuten leider nicht immer zu Herzen. Sie schreiben bis spät in den Abend Therapieberichte, klappern Ärzte $a b$ und lassen falsch ausgestellte Rezepte berichtigen, telefonieren in der Mittagspause mit Lehrern oder bilden sich an Wochenenden fort.

_ Gehen Sie in sich und überlegen Sie mal, wie viel Zeit Sie selbst investieren, die Sie nirgendwo abrechnen können. Wie oft es für Sie selbstverständlich ist, sich selbstlos für das Wohl Ihrer Klienten zu engagieren. Es scheint, als könne man das mit uns machen, weil wir schließlich einen sozialen Beruf gewählt haben. Wehren wir uns zu wenig, kämpfen wir zu wenig um unsere Rechte? Ich befürchte, ja.

- Es kann definitiv nicht angehen, dass wir als Ergotherapeuten immer nur in Vorlage gehen. Sei es bei der Therapie, die schlimmstenfalls nicht vergütet wird. Sei es bei Fortbildungen, die wir oftmals selbst teuer bezahlen und hinterher nicht einmal mehr Geld für unser verbessertes Angebot verlangen können. Oder sei es bei den erworbenen akademischen Abschlüssen, die uns anschließend nicht zwingend mehr Gehalt bescheren.

_ Unsere Investitionen sind hoch - emotional, zeitlich und finanziell. Aber wann sich unsere Leistung auch in unseren Geldbeuteln bemerkbar machen wird, bleibt offen. Da hilft nur eines: Nicht alles als gegeben hinnehmen, auf die eigenen Kompetenzen vertrauen und sich in Zukunft öfter mal selbstbewusst gegen Ungerechtigkeiten wehren. Denn: Auch der Flügelschlag eines Schmetterlings kann manchmal einen Sturm entfachen.

Mut, Optimismus und gutes Geld für Ihre hervorragende Arbeit wünscht

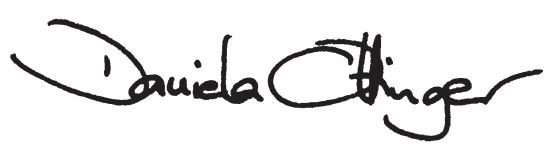

\section{ZU GEWINNEN}

Kursplatz

1 „Grafomotorikkurs“ Seite 45

Bücher

2-mal „Sturzprävention in Therapie und Training“"

5-mal „Warum ist

Mama traurig?"

4-mal „Zwischen Himmel und Erde"

Und außerdem ...

1 Box-Set 